\title{
COMPARATIVE ANALYSIS OF GAS PURCHASE CONTRACTS
}

\author{
GARY A. HOLLAND*
}

\begin{abstract}
Gas Purchase Contracts, like all other contracts in the oil and gas industry, are constantly in the process of evolution and there are many existing forms of Gas Purchase Contracts. This article consists of a comparative analysis of the provisions of four GasPurchase Contracts in use in the natural gas indus. try. The article commences with a discussion of a clause that has only recently been included in Gas Purchase Contracts in Western Canada, the prepayment clause, indicates possible income tax problems arising out of the clause and considers provisions with respect to repayment of the prepayment. The article then discusses the most favoured nations clause and points out that it is important to determine the extent of the applicability of the clause to the provisions of a subsequent contract. The article concludes with an analysis of the remaining clauses in a typical Gas Purchase Contract.
\end{abstract}

\section{A. INTRODUCTION}

For this analysis of gas purchase contracts in use in Western Canada, the contract forms examined are those that have been used by Trans-Canada Pipe Lines Limited, Alberta and Southern Gas Co. Ltd., Westcoast Transmission Company Limited and Northern Natural Gas Company. The contract forms used by these four major purchasers have changed to some extent over the past ten years and for that reason the various provisions of the contracts referred to in this analysis may not have been included in the contracts of the various companies at any particular time. ${ }^{1}$ Generally, however, the forms of contracts used since the middle of 1969 have been compared for this analysis.

Two of the main features of gas purchase contracts that are of particular concern today to producers in Western Canada are the most favoured nations provision and the interest-free loan or prepayment provision. This analysis will first compare these two provisions and will thereafter compare the various other provisions of the gas purchase contracts.

\section{B. COMPARISON OF PREPAYMENT PROVISIONS}

The idea of an interest-free loan or prepayment to be made by the purchaser to the producer was introduced into gas contracts in Canada in the middle of 1969 by Northern Natural. ${ }^{2}$ This was an effort by Northern. Natural to make more attractive the offer to purchase that was being presented to various producers by Northern Natural and thereby establish Northern Natural in the gas purchasing business. The prepayment provision also coincided with a significant increase in the price being offered by all the major gas purchasers. The prepayment provision was attractive to the producers as they could immediately get cash with which to carry out further exploration or development work in areas such as the deep foothills where drilling and exploration is much more expensive than on the flat lands of Alberta. Since the introduction of this contract provision by Northern

\footnotetext{
- Barrister and Solicitor, Law Department, Gulf Oil Canada Limited, Calgary, Alberta.

1 For an example of a Gas Purchase Contract, see Lewis and Thompson, Canadian Oil and Gas, Vol. 1, Div. C, Form C. 11 (a).

2 See Meyers, Commentary on the Papers Presented at the Ninth Annual Oil and Gas Seminar, (1971) 9 Alta. Law Rev. 445, for a discussion of the Lessor's interest in the prepayment to the Leassee.
} 
Natural, Alberta and Southern and Trans-Canada have also offered prepayment provisions either as a part of their gas purchase contracts or as a separate agreement collateral to the gas purchase contract.

It is desirable to have the prepayment provision set out in the main contract rather than in a separate agreement, but if a separate ancillary agreement is utilized, then that separate agreement should recite that the prepayment provision is granted as part consideration for the execution of the gas purchase contract and the separate prepayment agreement should be dated the same day as the gas purchase contract. In this way the possibility is avoided of having the prepayment agreement declared invalid by reason of there being no consideration or because of past consideration. It is the practice of Northern Natural to set out the prepayment provision as a clause in the gas purchase contract. Trans-Canada and Alberta and Southern follow the procedure of utilizing a separate agreement.

It is important to ensure that there is no income tax problem with respect to the prepayment provision. The Northern Natural form of prepayment clause refers to the prepayment as a prepayment for gas to be supplied under the contract. It would be preferable to utilize language that describes the prepayment as a loan and specifies that the loan is interest-free. If the payment is described as a prepayment, then it is necessary for the producer to assert for income tax purposes that the prepayment is a loan even though it is called a prepayment; or assert that the prepayment is on account of goods not yet delivered thereby entitling the producer to utilize Section 85B (1)(c) of the Income Tax $\mathrm{Act}^{3}$ and deduct the prepayment from income for the year in which it is received. But if the prepayment is called a loan, then the problem does not arise and the purchase price is considered income as the production is taken.

There is an additional question relating to the use of Section 85B (1)(c) of the Income Tax Act as this section permits the taxpayer to deduct a "reasonable amount as a reserve" in respect of goods to be delivered after the end of the year. There is no certainty that a "reasonable amount" is the full amount of the prepayment. In order to avoid the problem it is desirable to call the prepayment an interest-free loan.

If the purchaser, or the companies to whom the purchaser resells the natural gas, are subject to the jurisdiction of the Federal Power Commission of the United States, there is an additional consideration with respect to prepayments. If the prepayment is called a loan then it is not certain, at this time, that the cost of that loan can be included in the rate base of the company that is subject to Federal Power Commission jurisdiction. This question may be settled in the near future as on January 23, 1970, the Federal Power Commission issued a "Notice of Rule Making" (Docket R-380) pursuant to which the Federal Power Commission will hold hearings prior to ruling as to whether prepaid loans can be included in the rate base as a cost indirectly associated with the acquisition of gas. At the present time the uncertainty of this matter will affect the contracts with Northern Natural but not the contracts with Alberta and Southern. 
The Northern Natural prepayment clause provides that the producer is to receive 1.5 million dollars for each 100 billion cubic feet of the producer's recoverable gas reserves and the contract elsewhere provides for the determination of the recoverable gas reserves. The recoverable gas reserves are continually redetermined during the time prior to initial delivery; however, Northern Natural limits its liability for making the prepayment to a maximum of 2.5 trillion cubic feet for all producers in the particular area that are under contract to Northern Natural. Once the amount of the prepayment based on the 2.5 trillion cubic feet has been paid by Northern Natural with respect to reserves in the contract area, then Northern Natural does not have further liability and the prepayment for the 2.5 trillion cubic feet is apportioned among all the producers from the area under contract to Northern Natural. However, if the producer does not get a prepayment for any reserves, then those reserves are released from the contract.

The Alberta and Southern prepayment agreement, which is a document separate from the gas purchase contract, sets out a fixed amount for the pre-production loan, which amount is presumably calculated by reference to the recoverable reserves thought to underlie the producer's lands.

The Trans-Canada prepayment agreement is also a separate document from the gas purchase contract and the prepayment is described as a "prepayment for gas to be delivered" under the gas purchase contract and is described as a fixed amount for each thousand cubic feet of the seller's reserves. Provision is made in the TransCanada form of gas purchase contract for the determination of the seller's reserves by arbitration, if necessary, and these provisions would be adopted for the purposes of determining the amount of the prepayment. The Trans-Canada form also provides for the redetermination of the seller's reserves on the first and second anniversary dates under the gas purchase contract and for the consequential adjustment of the prepayment.

No Westcoast contract relating to prepayment was available for comparative analysis.

\section{COMPARISON OF REPAYMENT OF PREPAYMENT PROVISIONS}

Northern Natural is entitled to recover the prepayment out of one-third of the producer's min-day volume plus one hundred per cent of any revenue attributable to volumes taken in excess of the min-day volume. The actual words used in the Northern Natural agreement are: "Northern shall be entitled by way of recovery of prepayments hereunder to recover the proceeds of $33-1 / 3$ per cent of the seller's contract volume for that year." It is assumed that this provision entitles Northern Natural to withhold, out of the monies that would otherwise be paid to the producer, amounts equal to onethird of the price of the min-day volume and all of the purchase price for the volumes in excess of the min-day volume and to set off those monies against the prepayment.

If the Northern Natural contract is terminated, and Northern Natural has the right to terminate if the appropriate government permits are not obtained, then Northern Natural is entitled to recover the prepayment out of 25 per cent of the proceeds received by the 
producer upon the sale of the gas to some other purchaser. The copy of the Northern Natural agreement filed with the National Energy Board seems to have some words left out of this particular provision.4 In any case the section does not seem to be a grammatically happy clause. At the end of the tenth year after the initial deliveries have commenced, Northern Natural is entitled to recover the entire balance of the prepayment then outstanding if it has not previously been recovered under the provisions of the agreement.

The Alberta and Southern form of preproduction loan agreement provides that the producer shall repay to the buyer the whole of the said loan in monthly payments equal to the purchase price of onethird of all volumes delivered; the said monthly payment escalating, after a period of time, to one-third of the min-day volume plus one hundred per cent of the proceeds from the sale of volumes in excess of the min-day volumes. The Alberta and Southern agreement provides that if the gas purchase contract "shall for any cause be rendered impossible of performance", then the loan shall be repaid at a rate equal to one-third of the proceeds received by the producer from the sale of gas to any other purchaser. There is a general requirement that the balance of the loan is to be repaid at the end of ten years after initial deliveries if not previously repaid.

The Trans-Canada agreement provides that the "buyer shall deduct from each monthly payment... to be made by the buyer" under the gas purchase contract. In this way the contract sets out clearly the mechanics of the repayment. However, the method for determining the amount to be repaid each month is more complex under the Trans-Canada contract. During the initial period, which period is, in the case of the particular contract examined, determined by reference to the termination of certain requirements of the Oil and Gas Conservation Board (estimated to terminate about 5 years from the date of initial deliveries), Trans-Canada is entitled to recover monthly, the lesser of 50 per cent of the monthly payment that would otherwise be paid to the producer or an amount equal to the balance of the prepayment outstanding divided by 60 less the number of months during the period since initial deliveries. This calculation would effectively repay the prepayment over the 5-year period, assuming that the monthly amount did not exceed 50 per cent of the monthly purchase price of the gas.

After the expiration of the initial period, Trans-Canada is entitled to deduct the greater of one-third of the monthly min-day gas payment and one hundred per cent of the revenue for the volume in excess of the min-day volume, or an amount determined by the same sort of formula as referred to earlier, so long as the formula amount does not exceed fifty per cent of the monthly payment. The TransCanada agreement provides for total repayment at the end of 10 years if the prepayment has not by then been repaid.

The Trans-Canada contract does not have a provision such as con-

- National Energy Board Application of Consolidated Natural Gas Limited and Consolidated Pipe Lines Company, August 28, 1969, Volume 1, Contract 1, Article III, Section 5, provides as follows:

In the event of termination as aforesaid, Seller agrees to refund to Northern all amounts paid by Northern to Seller, including amounts paid by Northern after the date of termination, $25 \%$ of the proceeds received by Seller from the subsequent sale of gas produced from Seller's Lands; provided that to the extent Northern has not recovered all its prepayments at the end of ten (10) years after initial delivery, Seller shall refund the prepayments then outstanding. 
tained in the Alberta and Southern or Northern Natural contracts providing for repayment in circumstances where the gas purchase contract is terminated or rendered impossible of performance. The Trans-Canada prepayment is stated to be "concurrent" with the gas purchase contract but is not part of the gas purchase contract. It would appear that the prepayment agreement would continue notwithstanding that the gas purchase contract was terminated or had become impossible to perform. The most significant difference between the Trans-Canada contract and the forms used by Alberta and Southern and Northern Natural is that the amount that the purchaser is entitled to recover each month under the Trans-Canada contract is fixed by the agreement, whereas under the Alberta and Southern and Northern Natural agreements if the buyer wants to recover more than onethird of the monthly gas purchase price, the buyer must demonstrate to the seller's satisfaction that the buyer is not able to recover the prepayment out of one-third of the purchase payments made during the initial 5 years.

\section{COMPARISON OF MOST FAVOURED NATIONS PROVISIONS}

The most favoured nations clause gives the producer the right to adopt the terms of any other contract that the purchaser enters into during some succeeding period of time. The period usually commences on the date of the contract and continues either for a fixed number of years thereafter or for a period that will be determined by a Conservation Board order relating to the continued production of gas. The favoured nations clause may relate only to the basic price that is offered by the purchaser in a subsequent contract, or alternatively, the producer may be allowed to adopt all the applicable provisions of the subsequent contract.

From the producer's point of view, it is desirable that the favoured nations clause apply to all applicable provisions of the subsequent contract and not just to the basic price provision. If the favoured nations clause is restricted to allowing the producer to adopt only the basic price, then the purchaser could enter into subsequent contracts for the purchase of gas at the same basic price but make some other provision in the agreement, such as prepayment or currency adjustment, of such a nature that would in effect provide the producer under the subsequent contract a higher total price but would not allow the producer under the prior agreement to adopt that advantage. If the favoured nations clause applies only to the basic price, then it is possible for the purchaser to adjust other parts of subsequent contracts so as to effectively increase the amount being paid to the producer under a subsequent contract without triggering the various favoured nations contracts under which that purchaser is then obligated.

As a further general comment, the favoured nations right should be granted as part consideration for the gas purchase contract. Ideally, the favoured nations clause is incorporated into the gas purchase contract, but it is the practice of some gas purchasers to utilize an ancillary letter agreement which is separate from the gas purchase contract in order to grant the most favoured nations right. If the separate agreement is utilized, the letter should recite that the most favoured nations clause is granted as part consideration for the execution of the gas purchase contract and the separate ancillary agreement 
should be dated the same day as the gas purchase contract. In this way a producer would avoid having the favoured nations right declared unenforceable by reason of there being no consideration or because of past consideration.

One of the very few cases concerning gas purchase contracts in Canada considered the favoured nations clause. The case of Permo Gas \& Oil Limited v. Pacific Petroleum Ltd. ${ }^{5}$ concerned a gas purchase contract of Westcoast Transmission and the contract provided that if Westcoast entered into any contracts for the purchase of gas with any producer within the Peace River area of British Columbia during the term of the contract 6

... upon terms more favourable to such producer or producers than the terms
hereof, Seller shall have the right upon notice in writing to the Buyer to have this
contract modified so as to make applicable to the sale and purchase of gas here-
under such more favourable terms as are contained in the said contracts with the
said producer or producers.

Westcoast Transmission subsequently entered into an agreement with another producer in the same area and under the subsequent contract the price paid for residue gas was higher than under the Permo contract. However, the amount paid under the subsequent contract for pentanes plus was lower than under the Permo contract.

The case considered the question of whether the expression "terms more favourable" meant each particular term of the subsequent contract or the subsequent contract taken as a whole. Permo argued that it was entitled to pick any term out of the subsequent contract and have it apply to the Permo contract. The Court held that price under the contract is a single term and is not divisible and must be taken as a whole and for the price term to be more favourable the whole price clause must be considered and not just the price of the residue gas. (The Westcoast contracts are different from the other contracts used by the major purchasers in that Westcoast buys all the products in the natural gas rather than just residue gas.) The Court went on to hold that the onus was on the seller to show that the total price provision in the subsequent contract was more favourable and that in the particular case the seller had failed to satisfy that onus.

The case is authority for the view that the most favoured nations clause is enforceable in Alberta if there had been any doubt on that point. But while Permo could show that the basic price for the residue gas was higher and therefore more favourable, because the price for the pentanes plus was lower, it was necessary for Permo to show that the price provision as a whole was more favourable and this Permo failed to do. The case seems to suggest, although it does not decide, that the producer could pick only the price provision and if the producer could show that the price provision in toto was more favourable, he would be entitled to adopt it. The Permo case stated:7

"Terms" is expressed in the plural. It does not follow that a single term may not be sufficient to bring the most favoured nations clause into operation. For instance, if all terms of two agreements except one are the same, one more favourable term would make the "terms" of that agreement "more favourable".

\footnotetext{
3 (1963) 43 W.W.R. 232.

- Id. at 233.

7 Id. at 236.
} 
This does not provide much help in deciding whether the seller must adopt all or simply the more favourable provisions of the subsequent contract. Accordingly, it could be argued that if, for example, the sulphur spec was higher in the subsequent contract, the producer would not need to comply with that higher sulphur spec in the subsequent contract but would need only to show that the price provision was more favourable.

The form of most favoured nations agreement utilized by Northern Natural is set out in a separate letter agreement and requires the total substitution of "the pricing and prepayment provisions and such other provisions having an effect on price," and further states that in making the "substitution all such pricing, prepayment and other provisions must be adopted." This form would appear to provide the greatest protection to the purchaser as a great number of provisions affect the price to some extent. This form of favoured nations clause would require the adoption of all or nearly all of the provisions of the subsequent contract. Certainly the rate of take as a function of reserves would be considered to have an effect on price. Similarly, the currency adjustment provision would affect the price.

The form of most favoured nations agreement utilized by Alberta and Southern is also a separate letter and refers to substituting "all applicable terms and conditions of such other gas purchase contract." The producer is required to take all or nothing of what is contained in the subsequent contract. The Alberta and Southern letter further makes express provision for substituting the provisions of any collateral agreement or prepayment agreement. If the most favoured nations agreement does not specifically refer to collateral agreements, such as prepayment, then the general right to substitute the provisions of a subsequent gas purchase contract would probably not include the provisions of a subsequent collateral prepayment agreement and the buyer is probably not required to disclose a subsequent collateral prepayment agreement.

Alberta and Southern also uses an alternative form of most favoured nations provision set out in its gas purchase contract. This provision, which is part of the general clause relating to price, provides that the buyer must advise the seller each year as to the weighted average of the "buyer's cost per Mcf" of gas purchased during that year from producers in Alberta. The seller is entitled to have the price for the gas purchased under the contract during the following year increased to that average cost. The term "cost per Mcf" is expressly defined to mean the purchase price per Mcf plus any adjustment for taxes as provided in the general price clause and the purchase price is compared on the same basis of quality, measurement and terms and conditions of delivery. The BTU content or sulphur content would affect the quality and any unusual transportation costs of the producer would be relevant to the comparison. However, the provision for currency adjustment can probably not be included in the comparison. The only adjustment to the purchase price is taxes and the only comparable factors are quality, measurement and delivery and this would appear to exclude the currency adjustment provision. Similarly, a subsequent prepayment agreement could probably not be included in the comparison. 
Trans-Canada utilizes a separate letter agreement to set out its favoured nations provision and that letter refers to Trans-Canada entering into a subsequent "gas purchase contract, including any ancillary agreement with regard to prepayment for gas to be delivered thereunder... under which the pricing provisions, including any prepayments" are more favourable. The provision applies to all subsequent gas purchase contracts entered into for production from $\mathrm{Al}$ berta. The producer is entitled to take all the new pricing provisions. It is questionable, however, that the BTU content or sulphur content specifications of a subsequent contract could be included in the comparison.

The form of most favoured nations clause utilized by Westcoast and examined for the purposes of this analysis is from an old form of contract used by Westcoast in 1959. The form is limited to more favourable gas purchase contracts in a particular area of Alberta but is in effect for the entire term of the original gas purchase contract and is not limited to a particular number of years after commencement of deliveries as in the case of the other most favoured nations agreements.

The terms of any subsequent contract "which are in the seller's opinion more favourable...than the terms" of the earlier contract may be adopted by the producer. The seller has "the right upon notice in writing to the buyer to have this contract modified so as to make applicable ... such more favourable terms."

This form of most favoured nations clause is very similar to the clause considered in the Permo case, but the essential difference between the clause in the Permo case and the form used in this 1959 contract by Westcoast is the Permo case form did not provide that it was in the seller's opinion as to whether or not the terms in the subsequent contract were more favourable. The agreement in the Permo case was executed in 1955 and the litigation took place in 1963. It appears that in the meantime in 1959 Westcoast had amended its contract form and thereby drafted itself out of the defense that was available in the Permo case. The Permo case held that where the contract provided an objective standard for determining whether or not the subsequent contract had more favourable terms, then the onus was on the seller to establish that the subsequent contract was in fact more favourable. The later form used by Westcoast in 1959 avoids the problem of determining the more favourable nature of the subsequent contract by permitting the seller to decide that question.

\section{E. COMPARISON OF OTHER PROVISIONS}

\section{Conditions Precedent}

All the contracts are conditional upon the happening of certain events. The contracts are designed for the purchase of gas for export from Alberta or British Columbia and each specifies the approvals required such as from the Alberta Oil and Gas Conservation Board and the National Energy Board. The Trans-Canada contract goes into some considerable detail as to the approvals required whereas the other three contracts recite generally that all government approvals as may be required must be obtained before the buyer is liable under the contract. The Westcoast contract provides that the liability of the buyer is conditional upon the buyer constructing certain 
pipeline facilities but there is no obligation on the buyer to construct those facilities. In the case of this contract Westcoast could unilaterally terminate the agreement if it so desired by not constructing the pipeline facilities. The inclusion of this unilateral right to terminate probably reflects the effective monopoly position of Westcoast as a gas purchaser in Northeastern British Columbia.

The Northern Natural agreement allows certain lands to be released from the contract if an export permit is not obtained for those lands. This provision does not appear in the other contracts. In the Northern Natural agreement ${ }^{8}$ there is a provision whereby Northern will pay for the minimum quantities to be purchased under the agreement for a period of 12 months after the agreement has been terminated for failure to get the appropriate government permits. This is a more generous provision than appears in the other contracts and is probably a function of Northern Natural in effect buying its way into the gas business in Western Canada. In practice the timing of the Northern Natural application for export permits is such that it would be unlikely that Northern Natural would become liable under the provision as the inability to obtain the appropriate government permits would be known to Northern Natural well in advance of Northern Natural's obligation to take deliveries under the contract.

The Westcoast contract provides for the release of certain lands having excess reserves and these lands would be severable from the contract.

\section{Reservations of the Seller}

All of the agreements provide certain rights and reservations to the seller. Of particular significance is the right of the seller to remove hydrocarbons other than methane subject always to minimum BTU content. The minimum BTU content requirement varies among the agreements and Westcoast requires the producer to leave a minimum quantity of pentanes plus per Mcf in the natural gas. (The situation under the Westcoast contract is different because the natural gas is being purchased prior to processing and involves the purchase of the other products obtained upon processing the natural gas.) All the agreements except Westcoast expressly reserve to the producer the right to sell gas to other people in order to prevent flaring of gas or the termination of the lease during periods of a force majeure or during the period prior to initial delivery. This right is not expressly granted to the producer under the Westcoast contract and it is doubtful that it can be implied.

\section{Quantity of Gas}

In the Trans-Canada contract the minimum daily quantity is defined as being the total reserves divided by the number of days of the contract. The total reserves are not specified but the agreement provides for the determination of reserves. The buyer is required to take and pay for, or pay for in any case, the minimum daily quantity. The buyer can elect to take up to 120 per cent of the min-day and that larger quantity is referred to as the maximum daily quantity. The buyer is entitled to get delivery of any gas paid for and not taken over the next 5 years. 
In the Alberta and Southern contract the total reserves are specified in the contract and the max-day quantity is 125 per cent of the min-day and the min-day is set out as an exact number. The buyer is required to take and pay for 100 per cent of the min-day. The buyer is entitled to take delivery of any gas paid for and not taken over the next 2 succeeding years.

Under the Westcoast contract the max-day is fixed as a specified volume by the contract and the min-day is 90 per cent of the maxday. Volumes paid for and not taken can be taken by the buyer over the succeeding 5 years. The Westcoast contract is unusual in that the gas which the buyer is required to pay for, if not taken, is not paid for until the following year, whereas under the other three contracts the minimum volume of gas must be paid for by the buyer during the current year.

The Northern Natural contract describes the yearly contract volume as being one million cubic feet for every so many billion cubic feet of reserves and the min-day volume is this yearly volume divided by the number of days in a calendar year. The max-day is 120 per cent of the min-day and the buyer is entitled to make up any gas paid for and not taken over the next 5 years. The general right of the buyer to make up gas paid for and not taken applies only after the buyer has taken the minimum contract volume in that particular year.

The Northern Natural contract has an additional provision with respect to making up volumes paid for and not taken prior to the initial deliveries under the contract. Northern Natural is entitled to credit one-third of the current volumes delivered under the contract (that is the min-day volume) against the gas paid for and not taken prior to initial deliveries. If Northern Natural believes that it will not, within 5 years after the commencement of initial deliveries, recover the full amount of gas paid for and not taken prior to initial delivery, then this one-third credit can be increased to a 50 per cent credit of the current daily volumes. The Northern Natural right is not expressly limited to recovery within the 5-year period after commencement of initial deliveries, but the provision seems to contemplate recovery during that period and the clause states that Northern Natural is entitled to use up to 50 per cent of current daily volumes in order to effect recovery within the 5 years. If the recovery is not effected during the 5-year period due to Nortern Natural utilizing the volumes in excess of the min-day for credits under the provision permitting recovery of gas paid for and not taken after commencement of initial deliveries, then there is a question as to the right of Northern Natural to continue to effect recovery after the expiration of the 5 years. Perhaps Section 3 (a) of Article V of the Northern Natural contract should not be construed as limiting recovery to the 5-year period, but it seems to imply that effect.

There is the additional question as to the rights of Northern $\mathrm{Na}$ tural where the inability of Northern Natural to recover fully under Section 3 (a) of Article V within the 5 years is attributable to utilizing the volumes delivered for the recovery of prepayments under Section 2 of Article III of the contract. Does this justify Northern Natural in using the 50 per cent level of credits rather than the 33 $1 / 3$ per cent level of credits to effect this recovery? Additionally, there 
is the basic question of whether the rights of Northern Natural to utilize current production for recovery of the prepayment under Section 2 of Article III and the right to use current production for the recovery under Section 3 (a) of Article $V$ for gas paid for and not taken after the commencement of initial deliveries are cumulative or non-cumulative. That is, can Northern Natural utilize one hundred per cent of the current volume in order to effect recovery under these two provisions? There does not appear to be anything in the contract to prevent Northern Natural from utilizing current production in this way.

\section{Failure to Deliver the Max-Day}

All of the four contracts provide for revision downward of the daily contract volume in the event that the producer is unable to deliver the max-day volume during a particular test period. Under the Trans-Canada contract the min-day volume is revised downward to $83-1 / 3$ per cent of the daily volume delivered during the test period. The Northern Natural agreement is the same. In the Alberta and Southern contract the min-day is reduced downward to 80 per cent of the average daily volume during the test period. Under the Westcoast contract failure to deliver the max-day results in the max-day being revised downward proportionate to the average deliveries during the test period. This would mean that the max-day volume then becomes the average volume delivered during the test period, and as the min-day is described as being 90 per cent of the max-day, the new min-day becomes 90 per cent of the average volume delivered during the test period.

\section{Quality}

The quality specifications, particularly as they relate to sulphur, are of importance to the producer. Natural gas is a very clean-burning fuel and as our society becomes increasingly concerned with pollution, the sulphur specs become increasingly important. The Alberta and Southern contract has a general specification requirement that the gas must be of "merchantable quality" and then goes on to set out particular specifications. The other agreements do not have this general requirement of merchantable quality. The Alberta and Southern contract provision of merchantable quality appears to override the particular specifications and is a specification in addition to all the particular specifications. The other contracts have only the particular specifications. The Trans-Canada and Northern Natural specifications relating to sulphur are one grain of hydrogen sulphide per 100 cubic feet and 20 grains of sulphur per 100 cubic feet. In the Alberta and Southern contract a specification of 1/4 grain of hydrogen sulphide and 2/10ths of a grain of sulphur is used. The Westcoast contract has no sulphur specification as the Westcoast contract purchases the gas prior to processing.

There is a question as to whether or not the Alberta and Southern contract permits the buyer to demand a better sulphur spec than the particular specification. Can Alberta and Southern claim that the gas is not of merchantable quality even though it meets the sulphur specifications that are specifically provided? There is the additional question of whether or not merchantable quality is a fixed standard at the date of the agreement or is a variable standard over the life of the 
contract, and with increasing legislation in the area of pollution, this is becoming an important consideration for the producer.

The Trans-Canada contract refers to the gas being commercially free of hydrogen sulphide containing not more than one grain per 100 cubic feet. From the manner in which the Trans-Canada contract is drafted, it appears that the one grain is the only standard required, notwithstanding the use of the expression "commercially free." The Westcoast, Alberta and Southern and Northern Natural contracts set out that the failure to meet the specifications permits the buyer to refuse delivery of the gas. The Trans-Canada contract does not specifically confer this right on Trans-Canada but there is probably little difference in the rights of the parties under the TransCanada contract notwithstanding that this right to refuse delivery is not specifically provided.

The Alberta and Southern contract provides that the buyer has the right to reduce the min-day to 80 per cent of the volume that can be produced at the specifications set out in the agreement. The question therefore arises whether this particular right of Alberta and Southern limits the right of the buyer upon failure of the producer to meet the specifications. The contract should be construed as limiting the rights of the buyer to the right to take this reduced volume. Presumably, Trans-Canada could terminate the agreement for failure to meet the specifications, but the producer would probably have the right under the Trans-Canada contract to demonstrate that the producer can bring the gas up to the specs and Trans-Canada would have to allow the producer some reasonable period to carry out the change.

\section{Measurement}

A point of interest with respect to the measurement provision is the use of standards established in the United States. For example, the metered volumes of natural gas are computed under all the contracts in accordance with the Gas Measurement Committee Report No. 3, American Gas Association, published in April, 1955. The TransCanada contract goes on to provide that if a Canadian standard is established by a governmental body having jurisdiction, that standard can be used.

The specific gravity of natural gas is, under the Trans-Canada contract, measured by a gas gravitometer. For specific gravity, the Westcoast contract adopts the American Petroleum Institute Code No. 50-A and Northern Natural adopts Chapter 7 of the American Gas Association Gas Measurement Manual. ${ }^{9}$ Alberta and Southern adopts the American Petroleum Institute Recommended Practice 50-A for specific gravity.

The heating value or BTU content measurement under the Alberta and Southern contract is in accordance with General Order No. 58-B dated December 28, 1955, published by the Public Utilities Commission of the State of California. Northern Natural simply sets out a particular specification for BTU content in the definitions. TransCanada has a standard recording calorimeter for BTU content and the Westcoast contract provides that the method for determining BTU content will be as agreed to by the parties. 
The dewpoint of the liquids in the natural gas is to be determined under the Trans-Canada and Westcoast contracts by an apparatus approved by the Bureau of Mines of the United States. Northern Natural has no standard apparatus and Alberta and Southern does not appear to cover this particular point.

Northern Natural and Alberta and Southern contracts provide that records of natural gas measurement must be kept for 6 years. Under Westcoast the measurements and meter records must be kept for 5 years. Trans-Canada has no express requirement.

\section{Price}

The price provisions in each of the contracts describe the initial price in various ways but are all substantially the same. The price redetermination provisions are more varied. Under the Trans-Canada contract a redetermination can be made after the 9th year of the contract and at 5-year intervals thereafter. If the parties are not able to agree to the price redetermination, then the matter can be referred to one or three arbitrators and the parties are entitled to produce evidence of anything they consider relevant to the question.

Under the Westcoast contract there is a general right of redetermination of price after 2 years and at 5-year intervals thereafter. In redetermining price "primary consideration" is to be given to the buyer's earnings. If the parties are not able to agree, the matter is referred to three arbitrators.

Northern Natural does not have any general right of redetermination of price. Alberta and Southern provides a right to a general redetermination after 8 years and at 5-year intervals thereafter. Upon failure to agree, a reference is made to three arbitrators and the price on redetermination is to be "the fair market value."

\section{Price Adjustment for BTU Content and Taxes}

Trans-Canada provides for adjustment of price if the BTU content is less than 1,000 or more than 1,125 . Westcoast has no adjustment in price for variation in BTU content, but the contract does provide for a reduction in volume if the BTU content is less than 950 .

The Northern Natural contract provides for adjustment of price for BTU content if the BTU content is more or less than 1,000. It would appear that there is always an adjustment under the Northern Natural contract, unless the BTU content is exactly 1,000. The Alberta and Southern contract is the same as the Northern Natural contract.

All the contracts except Westcoast provide for an adjustment for increased taxes on the gas.

\section{Currency Adjustment}

The currency adjustment clause may appear to be a rather inocuous sort of provision and as being merely an automatic adjustment depending on the exchange rate. However, this clause could be used to circumvent the most favoured nations provision of a contract where the most favoured nations provision is drafted so as to confine the right to basic price provisions of a subsequent contract. Trans-Canada has no currency adjustment, the whole contract being performed in Canada and the sale of the product being in Canada.

The Alberta and Southern agreement provides that there is no ad- 
justment if the exchange rate is between 105 and 95 U.S. cents per Canadian dollar. If the exchange rate exceeds 105 U.S. cents per Canadian dollar (that is if there is an increase in the value of the Canadian dollar relative to the U.S. dollar), then the price for the volume of gas sold for U.S. consumption is to be multiplied by 105 over the exchange rate. This will reduce the price paid for the gas in terms of Canadian dollars. If the exchange rate is less than 95 cents per Canadian dollar (that is a decrease in the value of the Canadian dollar relative to the U.S. dollar), then the price for the volume sold for U.S. consumption is multiplied by 95 over the exchange rate and this will increase the price paid in terms of Canadian dollars.

In the Northern Natural contract there is no adjustment in price when the exchange rate is between $971 / 2$ cents to $871 / 2$ cents U.S. for each Canadian dollar, and outside of these limits there is the same sort of adjustment as under the Alberta and Southern contract. Similarly, Westcoast uses the Alberta and Southern approach for currency adjustment.

As a purely hypothetical comment, a relatively simple change in this sort of clause providing, for example, that if the exchange rate is less than 100 U.S. cents per Canadian dollar the multiplier would be 100 over the current exchange rate (or over a fixed number such as 95), could effectively increase the price to the Canadian producer, but would not constitute an increase in the basic price paid under a contract, and accordingly would not bring into operation the most favoured nations agreements that relate only to the basic price paid under subsequent contracts.

All the contracts provide for a maximum adjustment and under the Alberta and Southern and Westcoast contracts there is a maximum adjustment of 1 cent, whereas Northern Natural has a maximum adjustment of 2 cents.

\section{Payments and Billings}

Under the Trans-Canada contract, in the case of gas to be paid for although not taken, payment is made within 60 days after the end of the particular contract year. The volume of gas that is to be paid for although not taken is determined on a yearly basis and the payment is made at the end of that year. The Northern Natural agreement provides that in the case of gas to be paid for prior to the initial delivery, the payment for that gas is to be made by the 10th day of the month following the month in which the gas was to be taken. With respect to gas not taken although paid for during periods after initial delivery, the Northern Natural payments are the same as Trans-Canada. Similarly, the Alberta and Southern requirement relating to gas to be paid for although not taken is 60 days after the end of the contract year. In the case of Westcoast, the agreement provides that Westcoast has the entire following year in which to make up any deficiencies in gas to be paid for if not taken, and the agreement further provides that if the deficiency is not made up during that following year, then the next January (that is two years later) the billing is to include the amount of gas that was to be paid for if not taken and that was not made up during the following year. 


\section{Force Majeure Clauses}

The description of what is a force majeure giving a right to the suspension of the obligations under the agreements is substantially the same in the four contracts and there are quite long descriptions of what constitutes a force majeure. However, the various exceptions to the general force majeure provisions have significant variations in them. The Trans-Canada contract provides that the party cannot claim the benefit of a force majeure to the extent that the failure to perform the contract was caused by the contributory negligence of that party. The Northern Natural contract provides that the party cannot claim the protection in the event of its "concurring negligence." It is not clear what the expression "concurring negligence" means.

The Alberta and Southern contract does not have this sort of exclusion from the force majeure provision, but it does seem to provide that if the force majeure results from the necessity of making repairs to wells or equipment, the necessity for those repairs must not result from the negligence of the party claiming the protection. This is only one possible interpretation of the clause dealing with the force majeure in the Alberta and Southern agreement. The Alberta and Southern clause is a long and complex sentence and as written it would seem that the words "not resulting from the fault or negligence of such party" modify only the description of making repairs to wells or machinery or pipelines and do not modify the other factors that can constitute a force majeure.

The Northern Natural agreement adopts the same sort of clause as utilized by Alberta and Southern. Both the Alberta and Southern and Northern Natural agreements specify that one of the conditions giving rise to a force majeure is "arrests and restraints of rulers and peoples." I rather think that such conditions would not occur in Canada but perhaps the people drafting those contracts are properly concerned with conditions in the United States.

\section{Warranty of Title}

There is substantial variation in the obligation imposed on the producer with respect to warranty of title to gas. Trans-Canada has the most realistic approach whereby the producer does not purport to have any better title to the gas than is provided under the leases pursuant to which the gas is produced. The other extreme is Westcoast under whose agreement the producer absolutely warrants title to all the gas delivered under the agreement. Alberta and Southern assumes a middle ground and under that contract the producer warrants title except for the failure of title through causes beyond the reasonable control of the producer. The Northern Natural agreement is very similar to Westcoast in that the producer warrants title and indemnifies the buyer against any claims of any nature relating to the title. All the agreements except Westcoast provide that the buyer can withhold the purchase price in the event that there is a defect in the seller's title. The Trans-Canada contract appears to be the most realistic approach to the title to the gas and is the sort of covenant that is exchanged between producers acquiring oil and gas properties. The extreme nature of the Westcoast contract may again be a result of the absence of competition for the purchase of natural gas in Northern British Columbia. 
[VOL. IX

\section{Determination of Recoverable Reserves}

All of the contracts provide for the parties to determine and redetermine the gas or the reserves of gas originally in place. The purpose of such a provision is that in each case the amount of gas that the producer is entitled to deliver under the agreement depends on the amount of reserves in place. In the Trans-Canada contract the daily volume is a direct function of the gas in place divided by the number of days in the contract. Under the Northern Natural agreement the daily volume is equal to one million cubic feet for every so many billion cubic feet of reserves originally in place. The Westcoast contract, although it fixes the maximum daily volume, provides for an adjustment of that volume upon redetermination of recoverable reserves. The Alberta and Southern contract provides specifically for the daily contract quantity and then provides for the adjustment of that quantity if the initial reserves dedicated to the contract are less than or in excess of the reserves originally thought to be dedicated to the contract.

The Alberta and Southern contract uses the expression "dedicating of reserves." It is the only one of the four contracts that uses this expression whereby the producer dedicates exclusively to the performance of the contract the reserves of the producer under certain lands. Using the expression of "dedicating" reserves to the performance of the agreement has been objected to by one commentator. ${ }^{10}$ The reason for this objection is not clear. It is unlikely that there is anything in law different in saying that the producer is "dedicating" particular reserves, as stated in the Alberta and Southern contracts, as compared to agreeing that the producer "reserves and sets apart for the exclusive performance" of the contract certain reserves, as stated in the Trans-Canada contract.

The Trans-Canada and Northern Natural agreements provide that if the parties are unable to reach agreement with respect to redetermining reserves, then the matter can be referred to arbitration. The Westcoast and Alberta and Southern agreements provide that where the parties are not able to agree upon the initial recoverable reserves, the matter is referred to an independent consultant or consulting firm. This is a different procedure from the general arbitration provisions of the Westcoast and Alberta and Southern agreements. These agreements do contain a provision for arbitrating matters arising under the contract and for the setting up of three arbitrators. However, this arbitration provision is not utilized for the purpose of determining and redetermining the recoverable reserves.

\section{Arbitration Provisions}

The Alberta and Southern arbitration clause relates to "Any arbitration provided for in this Contract or agreed to by the Parties." The price redetermination provision is the only matter specifically referred to arbitration.

The Trans-Canada arbitration clause relates to "Any controversy arising out of this Contract in any case where arbitration is expressly required under the provisions of this Contract." Price redetermina-

10 Gregg, Negotiating and Drafting Gas Purchase Contracts on Behalf of Seller, (1962) Thirteenth Annual Institute on Oil and Gas Law and Taxation 87 at 104 
tion and the redetermination of gas reserves are both specifically referred to arbitration.

The Northern Natural contract provides for arbitrating the redetermination of recoverable gas reserves. Westcoast uses the same form of clause as Alberta and Southern, and the Westcoast contract specifically refers only price redetermination to arbitration.

\section{Other Provisions}

In the so-called "Miscellaneous Clauses" Article in the Northern Natural contract there is a provision that does not appear in the other agreements whereby the producer grants to Northern "all requisite easements and rights-of-way over, across and under any lands that the seller has the right so to do." Northern is stated to have the right to perform on such rights-of-way any acts necessary or convenient in carrying out the terms of this contract. It is interesting to speculate the extent of the rights which Northern Natural may have acquired under this clause or if Northern Natural has in fact acquired any rights.

The Westcoast contract has a provision whereby the buyer agrees to establish rateable contract volumes as between all producers from a common reservoir based solely on the initial recoverable reserves. A comparable provision does not appear in the other contracts. This provision would require Westcoast, with respect to any given pool or field, to take gas at the same rate from each of the producers within that field. Probably, in practice that is going to be the way it is going to happen in any case, although the other contracts do not make specific provision therefor. 